\title{
Grußworte der Mitarbeiter des Lehrstuhles für Aufbereitung und Veredlung
}

\author{
Andreas Böhm \\ Leoben, Österreich
}

Wir, das mittlerweile große Aufbereiterteam der Montanuniversität Leoben - die Stammmannschaft aus Sekretariat, Uniassistenten, Labor und Technikum, projektfinanzierten Assistenten und wissenschaftlichen Mitarbeitern in Ausbildung - möchten auf diesem Wege Ihnen, Herr Prof. Flachberger (dir lieber Helmut) aufs Herzlichste zum 50. Geburtstag gratulieren.

Wir möchten diese Gelegenheit dazu benutzen, uns für die aufopfernde Projektakquisition und -organisation zu bedanken, um die Finanzierung und wissenschaftliche Arbeit unseres Mitarbeiterstabes zu ermöglichen.

Dieser Dank gilt Ihnen/dir auch in besonderem Maß für die aktive Arbeit, um das Betriebsklima so hervorragend zu halten, wie wir es am Lehrstuhl erfahren dürfen, und nicht zuletzt für die Strenge mit Augenmaß und Unerbittlichkeit in der Einhaltung von Terminen, die die qualitativ hervorragende Arbeit des Teams erst ermöglichen.

In diesem Sinne hoffen wir auch in Zukunft auf Ihre wissenschaftliche Tatkraft und Ihr Geschick im Umgang mit Menschen, wünschen Ihnen/dir und Ihrer/deiner Familie Gesundheit, und werden alles daran setzen, uns auch in Zukunft für das Team zu qualifizieren, denn es macht großen Spaß, ein Teil davon zu sein.

Ass.Prof. Dipl.-Ing. Dr. mont. Andreas Böhm 